\title{
La escenografía virtual en la retransmisión de grandes eventos
}

\section{Virtual sets in the broadcasting of major events}

\author{
Dr. Esteban Galán-Cubillo [C.V.] Profesor Asociado Universitat Jaume I Castelló. \\ esteban.galan@com.uji.es
}

Dr. Cesáreo Fernández-Fernández [C.V.] Profesor Contratado Doctor Universitat Jaume I de Castelló. cesar.fernandez@ com.uji.es

Resumen: En el año 2000, el experto en escenarios virtuales de la BBC, Danny Popkin, demandaba un mayor aprovechamiento de los escenarios virtuales en televisión. Diez años más tarde la situación es muy similar. La experiencia de las cadenas de televisión hasta el momento es que la escenografía virtual es una excelente herramienta para ahorrar costes de producción y que además ofrece ventajas en la realización de noticias, programas infantiles, espacios de televenta o en programas especiales de elecciones. Sin embargo, es necesario que la escenografía virtual ofrezca más verosimilitud y simplicidad en sus escenarios, una presentación de la información en tiempo real más atractiva y aportaciones creativas para formatos de entretenimiento. Para ello, en este artículo se analizan seis ejemplos de programas especiales, desde 1996 hasta 2009, que aportan novedades narrativas y estéticas que mejoran la calidad de los programas y la riqueza del lenguaje audiovisual.

Palabras clave: Escenografía virtual; estudio virtual; programa especial; televisión; escenario virtual.

Sumario: 1. Introducción 2. Hipótesis 3. Metodología 4. Consideraciones previas. 5. El uso de escenarios virtuales en programas especiales en televisión. (1996-2009). 6. Conclusiones

Abstract: In 2000, BBC virtual studios expert Danny Popkin criticized the television industry for not making a better use of virtual set technology. Ten years later the situation has not improved too much. Up to now, virtual set is just a good tool to save money and also offers advantages in the production of news, children's programming, commercials and election coverage. However, it is necessary that the virtual set enhances realism, improves presentation of information and increases entertainment. In order to reach such goals, in this article the author describes six examples of special programs, from 1996 to 2009, where the broadcasters found some ideas to improve the program quality and richness of the audiovisual language.

Keywords Scenery virtual; virtual studio; special programme; television; virtual set.

Summary 1. Introduction 2. Hypothesis 3. Methodology 4. Preliminary considerations. 5. Virtual sets in television special programmes (1996-2009) 6. Conclusions 7. Bibliography. 8. Notes. 


\section{Introducción}

Aunque los primeros experimentos de trabajo con croma-key se remontan en cine a la década de los 50, no es hasta mediados de la década de los 90' cuando aparece la escenografía virtual en televisión. En 1994, Ultimatte en colaboración con IMP presenta en el NAB el primer escenario virtual en tiempo real de la historia. De forma simultánea en España, la empresa de origen valenciano Brainstorm Multimedia, quien mediante un acuerdo de colaboración con Antena 3, lleva a cabo los primeros experimentos con la tecnología, en la producción de programas de televisión. Seguirían sus pasos TVE, Canal 9, TV3 y en definitiva, hoy ya todas las televisiones grandes y pequeñas cuentan con un plató dotado con un ciclorama verde o azul, en el que grabar programas con escenarios virtuales.

La televisión, con el uso de escenarios virtuales, encuentra su especificidad en el bit, que se convierte en el componente esencial de los equipos de producción y de la puesta en escena televisiva. El proceso de digitalización de la producción y la emisión televisiva consolida un entorno audiovisual íntegramente digital. En este nuevo escenario la escenografía virtual se desarrolla como una tecnología que en esencia consiste en el proceso de incrustación o integración entre el foreground que es la señal de cámara y el background que es un entorno virtual generado por ordenador. El entorno virtual debe actualizarse a tiempo real para adaptarse a los cambios de la señal de cámara. El resultado ante el telespectador es una imagen uniforme.

\section{Hipótesis}

El autor durante sus más de seis años de investigaciones sobre el uso de escenarios virtuales en televisión, ha estudiado y constatado las ventajas tecnológicas y económicas que proporciona el uso de estos sistemas. Sin embargo, la parte creativa, fundamental en la producción televisiva, ha quedado siempre bastante olvidada. Los productores de televisión que se han acercado a la tecnología, lo han hecho con la idea de implementar un método de producción eficiente para el entorno digital. El uso de escenarios virtuales ha permitido optimizar los recursos humanos y técnicos, posibilitando la realización de varios programas en directo, en un mismo día y desde un mismo estudio.

Partiendo de esta realidad, en este artículo se analiza el uso de escenarios virtuales en la realización de programas especiales en televisión, desde 1996 hasta la actualidad. En este tipo de programas, se han encontrado usos y aplicaciones de la tecnología que sí aportan soluciones visuales novedosas al lenguaje televisivo y que nos presentan una tecnología con una especificidad representativa propia, con un excelente futuro y con grandes posibilidades de ofrecer a la televisión un espacio de representación propio, liberándose así del lastre teatral y cinematográfico que ha encorsetado su discurso durante más de seis décadas.

\section{Metodología}

El autor ha llevado a cabo un proceso de observación del trabajo con escenarios virtuales en televisión desde 2004 hasta la actualidad. Para este artículo se han analizado seis ejemplos de uso de escenarios virtuales en programas especiales en televisión. Todos estos programas tienen la característica común de haber sido emitidos en directo, 
en horario de máxima audiencia y en torno a un evento en el que la cadena de televisión se jugaba su imagen y prestigio. En todos ellos la elección del escenario virtual, no resulta azarosa, sino que es el producto de una apuesta clara por una tecnología que permite a la televisión ofrecer un tratamiento visual acorde con la relevancia del evento. El festival de Eurovisión, la boda real en Madrid y las elecciones a la presidencia de EEUU o al Parlamento europeo han sido algunos de los grandes eventos en los que se ha analizado el uso de escenarios virtuales.

\section{Consideraciones previas}

El trabajo de observación en canales de televisión nacionales y autonómicos españoles (2004-2009) ha sacado a la luz la correlación que existe entre la existencia de un equipo humano estable y la emisión en directo de una de una producción diaria. Disponer de un equipo estable beneficia otro tipo de producciones -como por ejemplo, los programas especiales que se analizan en el presente artículo-. Para que estos programas se puedan llevar a cabo, el estudio debe contar con la capacidad técnica suficiente como para abordar la producción de programas en directo con una cierta complejidad. Esta circunstancia se refleja en el siguiente cuadro.

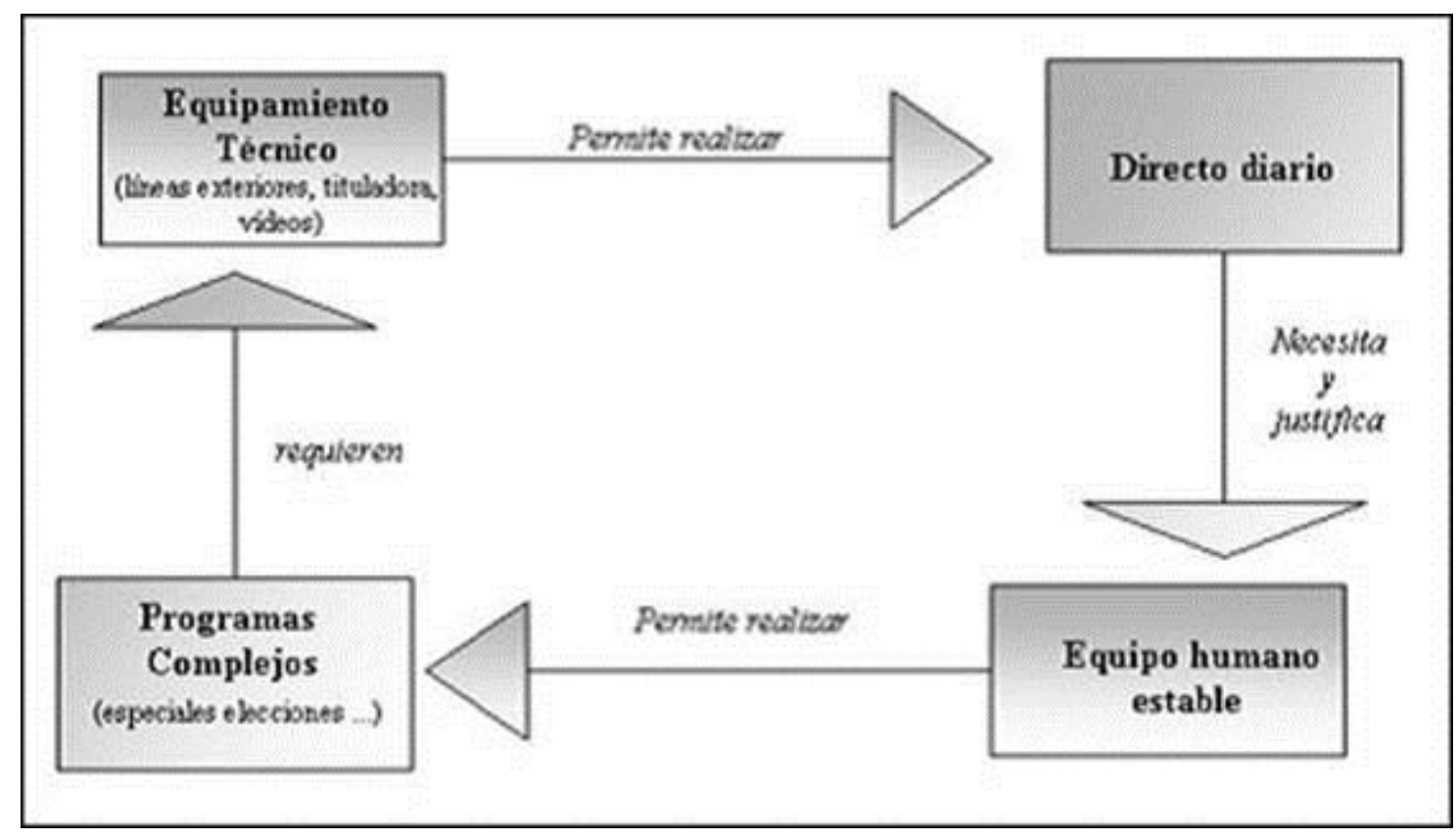

Tabla 1. Elaboración propia

Por tanto, el funcionamiento eficiente de un estudio de escenografía virtual se constituye en un cuadrado que se retroalimenta a través de sus cuatro vértices. Para lograr un buen aprovechamiento del estudio de escenografía virtual y una producción eficiente se puede optar por comenzar consolidando cualquiera de los cuatro vértices. Cada uno de los cuatro ítems que componen el cuadrado puede constituirse en una herramienta para obtener la excelencia en la producción. Plantearse, por ejemplo, la producción de un programa de gran formato exige unos medios técnicos adecuados, que a su vez permitirán realizar programas en directo. Los programas en directo exigirán disponer de un equipo humano estable que posibilitarán a su vez, plantearse la realización de programas de gran formato, cerrándose de esta forma el cuadrado. 
Un estudio de televisión con un funcionamiento óptimo debe contar en mayor o menor medida con esos elementos. Dentro de estos cuatro elementos se puede diferenciar entre aquellos puramente tecnológicos y aquellos que sirven como dinamizadores o de desarrollo de los aspectos tecnológicos.

\section{ELEMENTOS TECNOLÓGICOS}

Equipo humano estable

Estudio con posibilidades tanto en la tecnología virtual como en lo referente al potencial técnico al uso.

\section{ELEMENTOS DINAMIZADORES}

Llevar a cabo un programa diario en directo Llevar a cabo un programa especial de gran presupuesto.

\section{Tabla 2. Elaboración propia}

Del grado de cumplimiento de estos tres requisitos va a depender en buena medida el éxito de la relación calidad / coste de la producción. Disponer de un equipo estable se ha comprobado que evita fallos y retrasos en la producción. Además, contar con un estudio con el potencial técnico adecuado para el tipo de producción permite realizar los programas de un modo solvente sin necesidad de disparar los costes.

De todos modos, de los cuatro vértices mostrados en la tabla 1, el que más se ha trabajado es el relacionado con la posibilidad que ofrece la escenografía virtual de realizar programas en directo o falso directo con un coste muy inferior al que implica trabajar en un escenario real. Hasta el momento, las empresas de televisión no han estado interesadas en explorar todo el potencial creativo que brindan los sistemas de escenografía virtual (Galán, 2008). Sin embargo, sí se han llevado a cabo de forma aislada, usos de la tecnología de la escenografía virtual en programas especiales en los que sí que tiene un mayor peso el aspecto creativo. Estos programas especiales sirven al resto de incentivo y referencia visual.

Para la realización de este tipo de programas, en muchas ocasiones, es necesaria la adquisición de equipamiento adicional -cámaras, sensores, equipos de incrustaciónque después pueden ser amortizados en programas de pequeño formato. A continuación, se analizan algunos ejemplos de uso de escenario virtual en programas especiales, en los que en su momento se buscó obtener algún tipo de solución visual que ofreciera ventajas sobre los sistemas de representación preexistentes [1].

\section{El uso de escenarios virtuales en programas especiales en televisión. (1996-2009)}

1996. Festival de EUROVISIÓN en la NRK. La credibilidad de la integración. El estudio de este ejemplo tiene un extraordinario valor cualitativo porque es la primera apuesta solvente para la cobertura de un gran evento en directo con esta tecnología. 

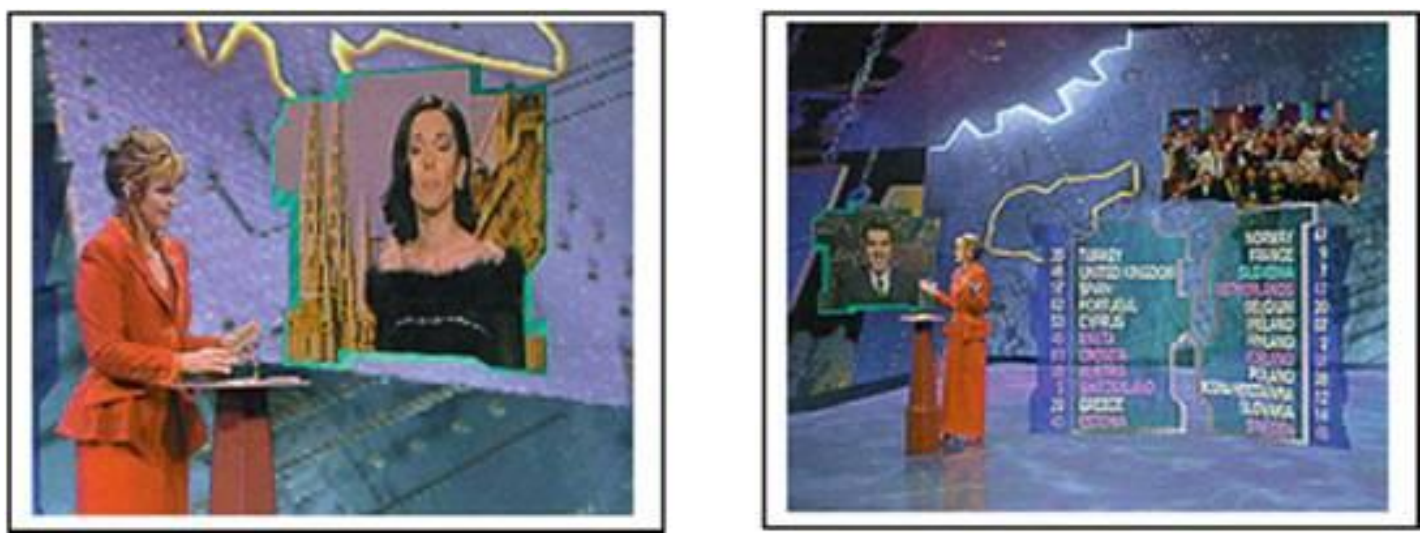

Ilustración 1. (Hughes, 1996)

Cuando en 1995 se plantea la posibilidad de retransmitir el Festival de Eurovisión utilizando escenografía virtual la premisa inicial era realizar todo el evento empleando un escenario virtual. Sin embargo, pronto se descartó esta posibilidad por la dificultad que implicaba que todos los artistas que actuaban se adaptaran a la interacción en un plató vacío de color azul. Por eso se decidió que la parte del programa en la que se empleara esta tecnología fuera la de las votaciones en la que solamente intervenía la conductora del programa. La navegabilidad de la presentadora podía ser entrenada a través de los ensayos (Galán, 2009). En las imágenes que aparecen como ejemplo, se observa la utilización de elementos reales como el atril o el vaso de agua.

Los resultados de la incrustación son sobresalientes. Se consigue una integración perfecta del vaso de agua; la sombra y el reflejo del atril y del vestido de la presentadora aparecen perfectamente proyectados en el escenario. La inclusión del vaso de agua no estaba prevista en un principio, fue una exigencia de última hora de la presentadora que se pudo solventar con éxito gracias a que el potencial del Ultimatte-8 que se empleó para realizar la integración no se había hipotecado previamente en otros menesteres. La incrustación del vestuario y del cabello de la presentadora ofrece una gran sensación de naturalidad.

En este hecho ha colaborado la elección del color rojo para el vestido, que no presenta ningún problema de brillos ni de contaminación con el color azul que se ha elegido como fondo de croma. Por otra parte, la elección de una tonalidad violeta en el escenario justifica cualquier tipo de contaminación azul que pudiera producirse como influencia del entorno. La elección del recogido en el peinado de la presentadora también simplifica la incrustación. En la utilización de entradas de vídeo en el decorado no se esconde en ningún momento su carácter virtual. La integración El público se integra en el escenario virtual en una ventana virtual en el decorado.

En conclusión, el diseñador ha logrado un espacio acogedor, atractivo y útil para presentar la gala, conectar con los diferentes países e informar de los resultados de las votaciones. Estas imágenes se han elegido porque pertenecen a la Gala de Eurovisión de 1996 (Hughes, 1996) y por tanto, permiten comprobar que, con creatividad e ingenio, se pueden vencer todas las limitaciones técnicas y realizar programas de calidad con escenografía virtual.

En 1996, la capacidad de las tarjetas gráficas para mover escenarios de gran calidad en tiempo real todavía era muy limitada y los sistemas de sensorización tampoco permitían 
demasiadas posibilidades. Sin embargo, pese a estos inconvenientes el resultado del programa es plenamente satisfactorio. La dificultad, entonces existente para dibujar en tiempo real escenarios realistas, se minimiza creando un espacio dominado por una estética inspirada en el movimiento surrealista. Los motivos oníricos y minimalistas que configuran el escenario no precisan de una gran resolución y detalle realista. Esta elección simplifica el trabajo de los motores gráficos. El único aspecto que no parece estar del todo articulado es la planificación del eje de mirada de la presentadora con respecto a los plasmas.

2003. Elecciones autonómicas en Canal 9. Presentación de datos en tiempo real a través del escenario virtual [2]

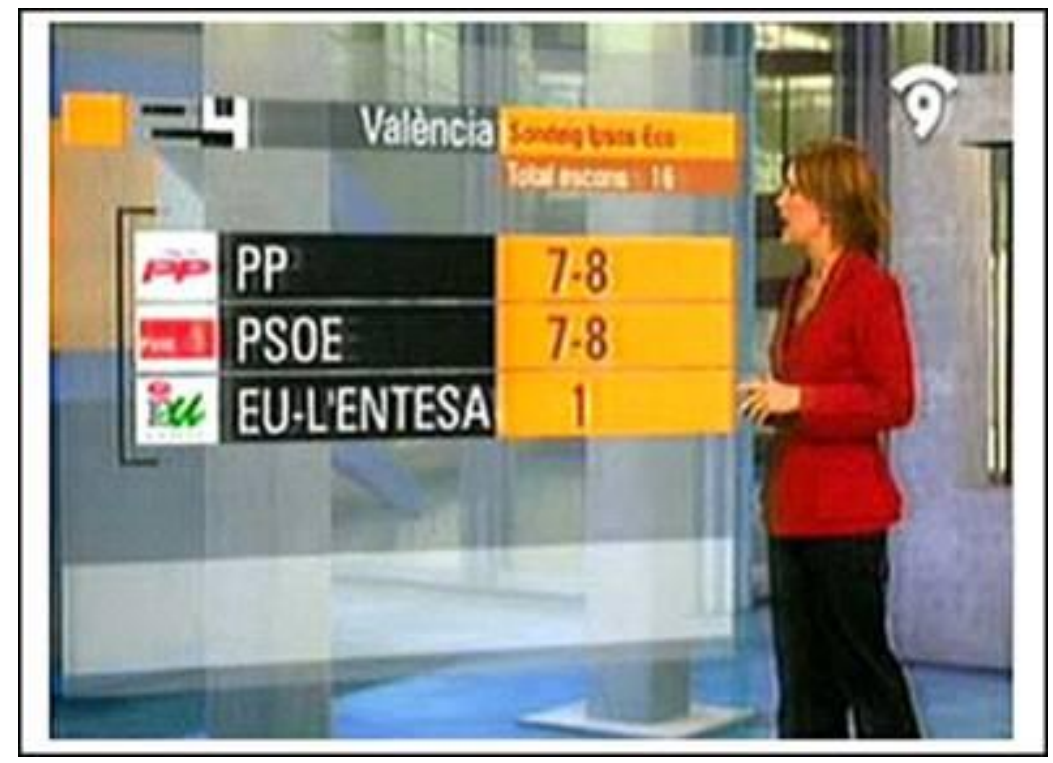

Ilustración 2. Cortesía de Brainstorm Multimedia.

En la imagen se observa cómo los datos se presentan en un plasma flotante y traslúcido. Pese a que el espectador detecta fácilmente que el decorado no es real, la forma de presentar la información resulta eficaz y elegante. El panel de datos no dispone de un soporte físico que justifique ante los ojos del espectador su origen real. Sin embargo, en la concepción del escenario no se rechaza de plano el uso de referentes reales. Para conferir mayor credibilidad al escenario se reproduce la configuración arquitectónica de un edificio real. El desaforo se construye a través de fotografías desenfocadas -para simular la profundidad de campo- que dan mayor sensación de credibilidad.

El decorado está compuesto por dos paneles en los que se presentan los resultados de las elecciones. Para cambiar de panel, al no disponer de tracking de desplazamiento de las cámaras, se emplea una plataforma de rotación que permite simular el movimiento de travelling. La plataforma de rotación surge en algunos estudios como una solución al problema de la limitación de espacio. Al disponer de un plató de pequeñas dimensiones donde hay poco espacio para desplazar las cámaras, la alternativa es mover al personaje; la sensación visual es idéntica. La plataforma tiene el objetivo de simular el movimiento de travelling de una cámara. La plataforma dispone de un control remoto para ejecutar el movimiento. En el modo automático la rotación se controla desde el software del 
escenario virtual donde se le pueden programar los grados de rotación -inicio y final- y el tiempo de duración -del que dependerá la velocidad del giro-.

2004. Especial Boda Real en TVE. La escenografía virtual muestra su potencial creativo al servicio de un gran evento.
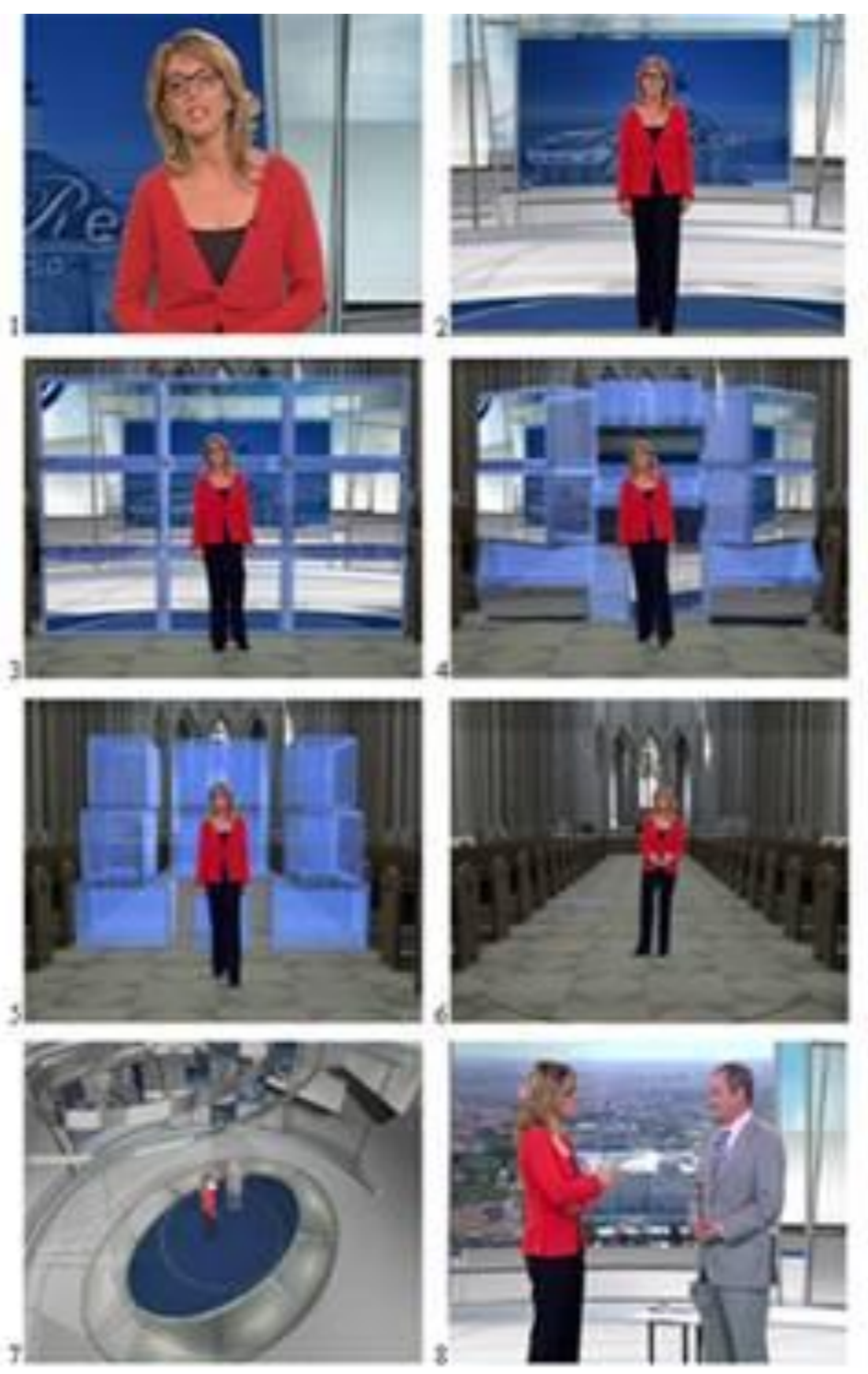

Ilustración 3. Cortesía de TVE

Las imágenes que se muestran en la ilustración anterior corresponden al programa especial que TVE llevó a cabo en 2004 con motivo de la Boda Real de los Príncipes de Asturias. Se ha escogido este programa para llevar a cabo el análisis, porque es un excelente ejemplo de utilización de escenografía virtual con fines creativos.

La incrustación es perfecta. Por ejemplo, en las imágenes 3, 4 y 5 en las que se muestra un plano completo de la presentadora, se observa cómo el zapato proyecta una sombra y 
un reflejo sobre el suelo del escenario. Este detalle, que puede parecer insignificante, otorga credibilidad a la composición final. La incrustación del vestuario y del cabello de la presentadora se ha resuelto con naturalidad. En este hecho ha colaborado la elección de los colores rojo y negro en el vestuario de la presentadora. Estos colores no ocasionan ningún problema de brillos ni de contaminación con el color verde o azul del fondo de croma. Además, contrastan a la perfección con las tonalidades grises y azules que predominan en el entorno virtual. También sirve de ayuda que las gafas de la presentadora sean de pasta negra, mucho más fáciles de incrustar que, por ejemplo, las gafas con montura al aire.

Sin embargo, un aspecto que sí que ofrece ciertos problemas de integración es el cabello de la presentadora. Como se observa en la imagen 1, el peinado está acabado con las puntas hacia fuera. Esto supone un inconveniente para la incrustación, porque quedan separadas partes muy finas del cabello que son difíciles de integrar. Sin embargo, este aspecto se ha resuelto con gran eficacia. Probablemente, se haya optado por introducir a través del incrustador Ultimatte, una cierta dosis de ruido (shadow noise) que permite que los bordes del cabello queden difuminados en el entorno, proporcionando una composición natural.

En la imagen 8 se observa la utilización de elementos reales en el escenario. Sin embargo, en este caso, el empleo de la mesa parece un accesorio postizo dentro del entorno. La inclusión la mesa no ha respondido a una opción estética, sino que obedece a la necesidad de tener un lugar accesible donde disponer del guión o de una copa con agua. En la utilización de entradas de vídeo en el decorado (imagen 8), no se oculta en ningún momento su carácter virtual. Cabe destacar la forma ovalada de la pantalla, perfectamente integrada en el escenario, así como la ausencia de cualquier elemento físico, que justifique la sujeción del plasma. Se ha optado por una utilización valiente del potencial creativo que ofrece la escenografía virtual, con un resultado verosímil.

En el plano cenital (imagen 7), llama la atención la combinación de círculos y óvalos en el diseño en planta del escenario. Este diseño además se aprovecha para integrar dentro del escenario la plataforma de rotación que simula el movimiento del travelling. El inconveniente de utilizar plataformas de rotación es que entre la plataforma y el suelo físico del plató, siempre existe una separación o pequeño borde que es difícil de integrar. Ante esta circunstancia se puede optar por disimular esta intersección con cinta del mismo color que el ciclorama del plató. Sin embargo, el inconveniente de esta solución para un programa en directo es que cuando la plataforma realiza el movimiento puede desprenderse parte de esa cinta.

La otra solución es diseñar un escenario en el que la plataforma quede disimulada por el propio suelo del escenario virtual. En las imágenes 2 y 7 , se puede comprobar cómo el escenario virtual presenta un anillo que sirve para disimular la intersección física de la plataforma. Sin embargo, en la parte inferior de la imagen 6 , se pueden comprobar los problemas de incrustación que provoca la plataforma.

El escenario se ha transformado del plató de televisión a la Catedral de la Almudena y por tanto, el cambio de textura del suelo deja al descubierto la intersección de la plataforma. En esta imagen 6 ya ha finalizado la mutación que experimenta el escenario al pasar del set convencional del programa, al interior de la Catedral de la Almudena. Todo ello se produce en tiempo real y ante los ojos del telespectador. Este efecto visual 
sólo puede obtenerse a través de la escenografía virtual. El cambio de entorno va además mucho más allá de un mero artificio visual. Los días antes de la Boda Real, la Catedral permanece cerrada al público con objeto de ultimar los preparativos del acontecimiento. La reconstrucción virtual en $3 \mathrm{D}$ de la Catedral sirve para que la presentadora ofrezca al espectador la posibilidad de pasearse de forma virtual por el interior del espacio en el que se desarrollará la Boda Real. Imágenes cortesía de TVE.

2005. Especial Elecciones BBC. La escenografía virtual como eje central del guión del programa.

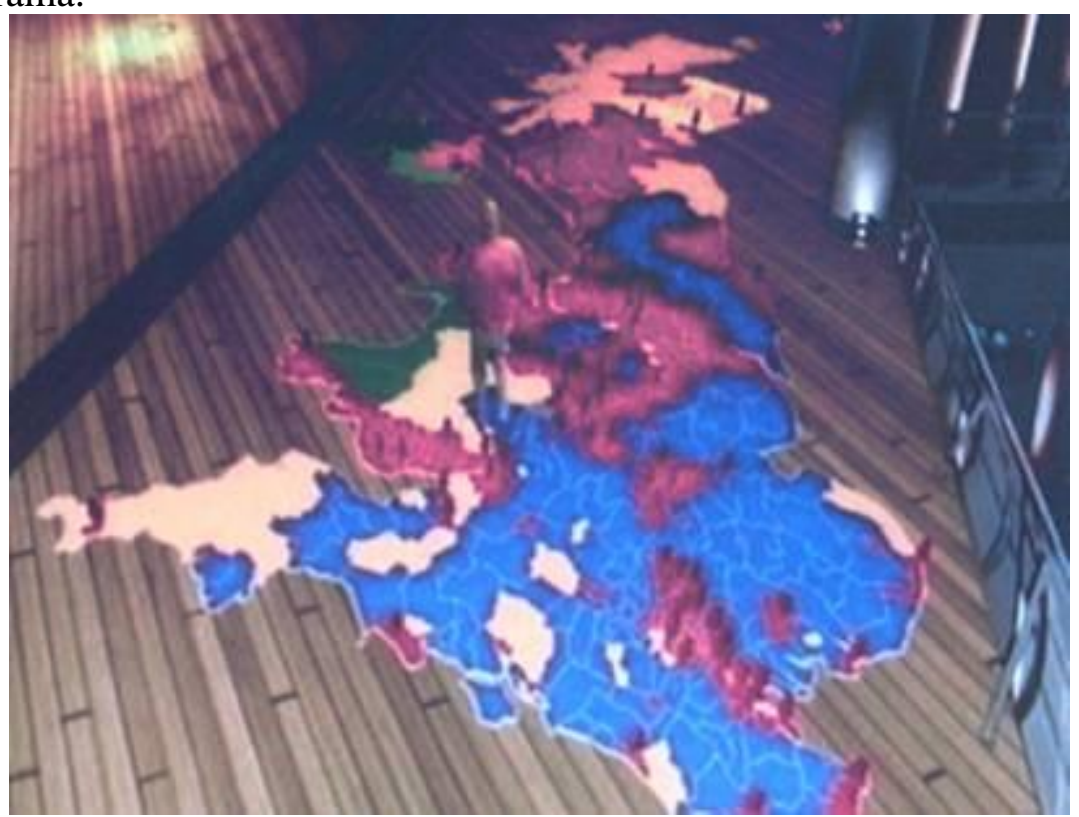

Ilustración 4. El presentador Peter Snow se pasea por un mapa virtual donde se representan los escaños. Fuente Brainstorm Multimedia.
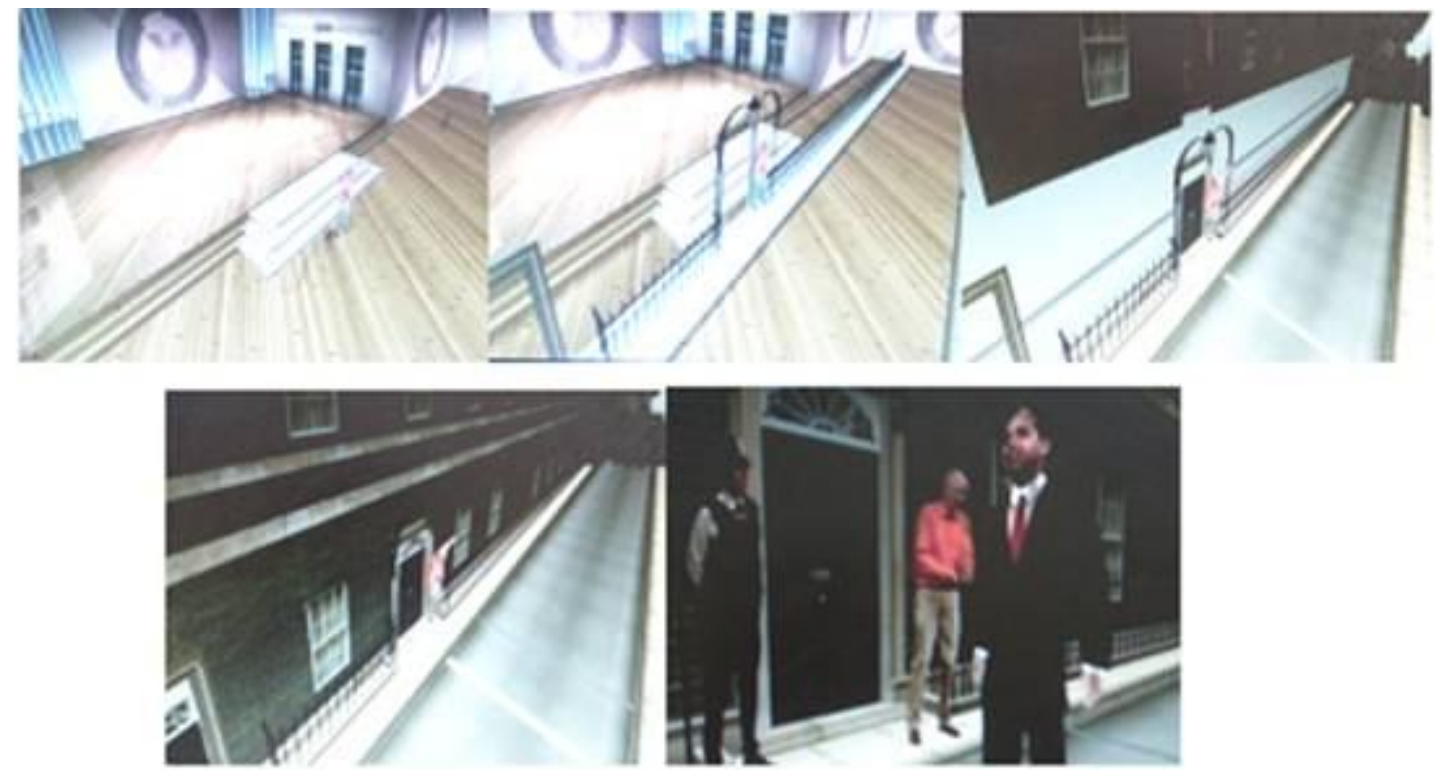
Ilustración 5. En esta secuencia de imágenes se observa la transformación que se produce a tiempo real entre el plató de televisión y la residencia del Primer Ministro británico en Downing Street, donde se representa una carrera entre los diferentes candidatos. Fuente Brainstorm Multimedia Elecciones 2005.

En este programa especial de elecciones, se llevaron a cabo una serie de recreaciones de espacios reales a través de entornos virtuales que servían al presentador para dar a conocer de una forma gráfica los datos de última hora [3]. La mayor dificultad del programa residía en la navegabilidad del presentador. Sin embargo, la implicación y complicidad del conductor Peter Snow con la tecnología y los numerosos ensayos que se llevaron a cabo facilitaron la comodidad del presentador con el entorno.

2008. Especial elecciones BBC News. El virtual, escenario de una cita con la historia [4].
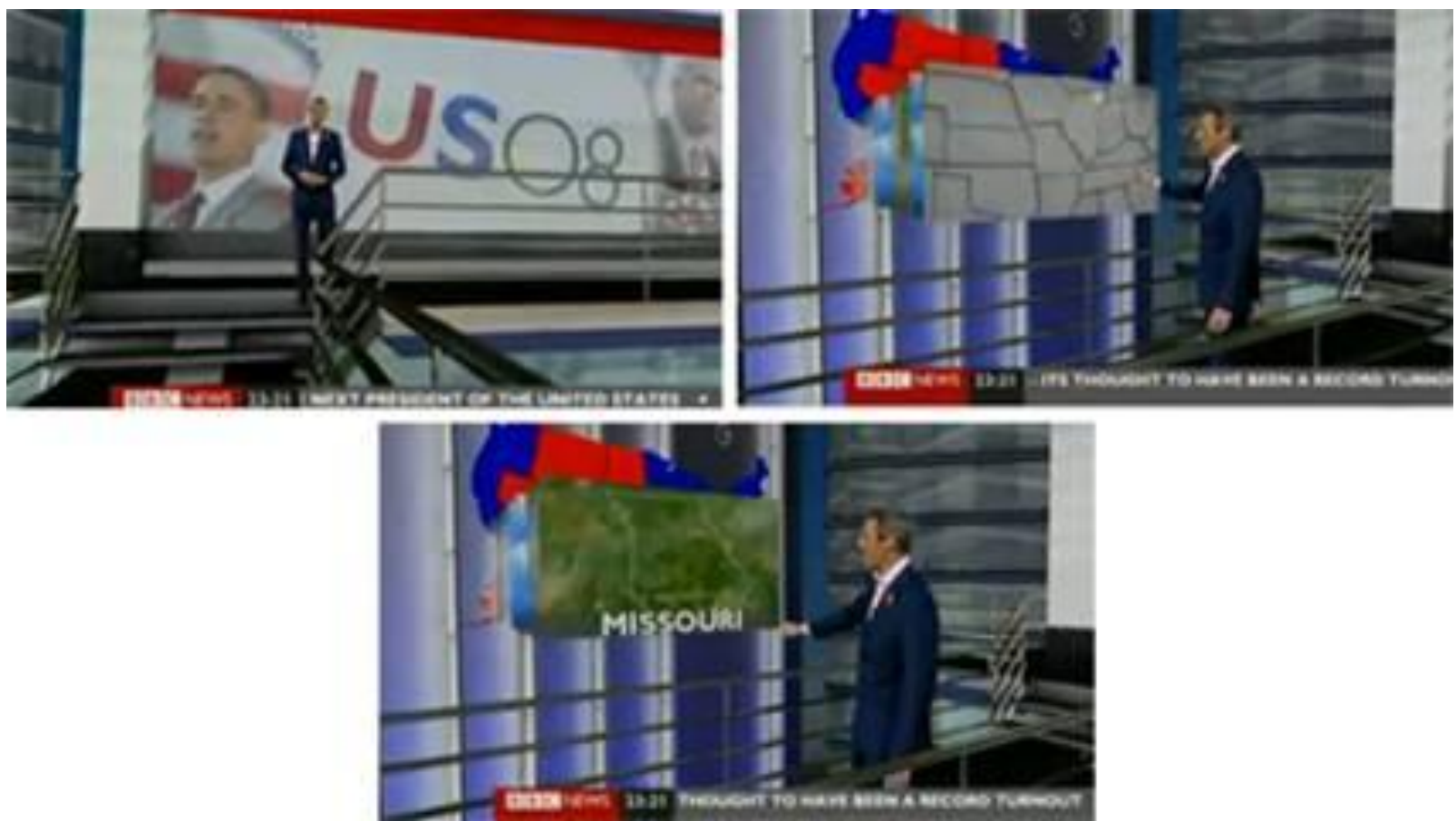

Ilustración 6. Cortesía de Brainstorm Multimedia

En este ejemplo, el escenario virtual se constituye en un excelente ejercicio de demostración del potencial representativo a través de una escenografía en la que se busca crear un entorno hiperrealista con colores saturados y texturas metálicas. El presentador desciende las escaleras y acude a la posición en la que interactúa con los gráficos para presentar los datos. Hay una clara vocación de puesta en escena con un objeto espectacularizante. La escenografía virtual dispone de los motores gráficos necesarios para presentar en tiempo real grandes arquitecturas. Este entorno grandioso que rodea al espectador, subraya y enfatiza la relevancia histórica y fundamentalmente mediática que tuvo la elección del senador Obama como presidente de los EEUU. 
La principal apuesta a nivel tecnológico es la capacidad que tiene el presentador de interactuar en tiempo real con los objetos 3D que se presentan en el escenario El presentador señala el objeto lo puede desplazar e ir presentando la información al tiempo que interactúa con ella [5].

BBC. ELECCIONES EUROPEAS 2009. La simplicidad ¿un síntoma de madurez?

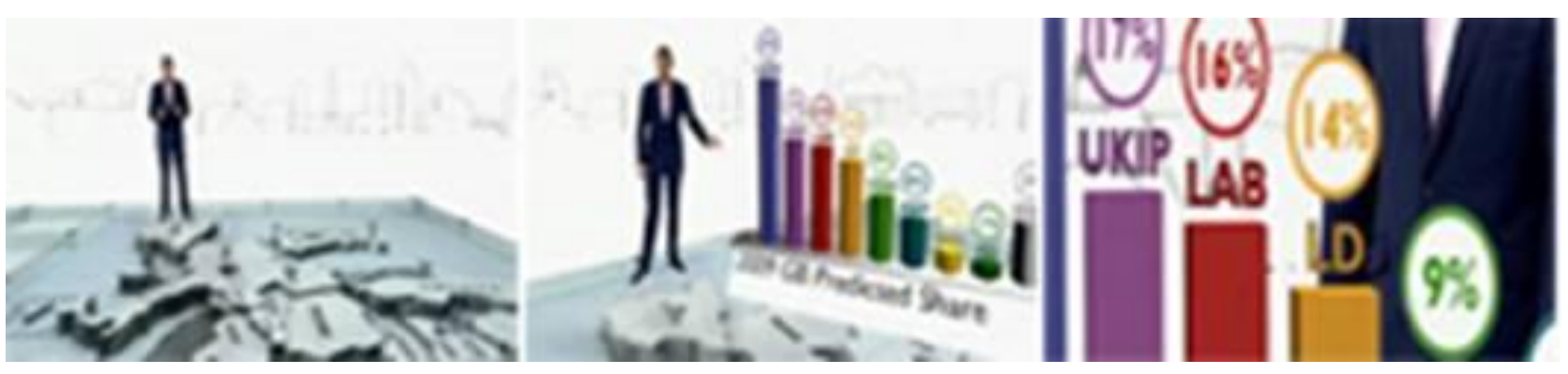

Ilustración 7. Cortesía de Brainstorm Multimedia.

En la ilustración 7, se ha renunciado a la escenografía realista. El presentador está sobre un mapa de la Unión Europea y el decorado es de color blanco silueteado con algunos iconos significativos de los países miembros de la Unión Europea. Los gráficos con la información electoral se dibujan en 3D en tiempo real sobre el suelo del plató. El presentador interactúa con la información, señalando y enfatizando aquellas partes del gráfico más relevantes. Con respecto a trabajos anteriores, se observa la mejora en la resolución de los gráficos. Para mostrar los detalles de la información no es necesario introducir un vídeo a pantalla completa. Basta con que una de las cámaras encuadre el detalle del gráfico que se desea enfatizar. En este escenario, no se ha buscado una mímesis con la realidad.

El escenario virtual no necesita parecer real sino que adopta una especificidad icónica propia. Sin embargo, al igual que ya ocurría en el ejemplo de Eurovisión trece años antes, el presentador no mantiene el eje de mirada para mostrar el gráfico. La mirada, en lugar de dirigirse hacia el elemento que señala, se dirige hacia el monitor que utiliza como referencia para contemplar la incrustación del escenario virtual. La asignatura pendiente sigue siendo la navegabilidad del presentador. Es decir, aunque tecnológicamente es posible que el presentador interactúe con objetos virtuales, todavía no se han implementado de forma suficiente soluciones tecnológicas que faciliten que el presentador pueda desenvolverse de forma fácil y cómoda en el entorno virtual.

\section{Conclusiones}

Los seis casos analizados tienen en común que el escenario virtual constituye un elemento decisivo del programa. El entorno virtual es un lugar donde el relato del programa avanza, se transforma y se enriquece. En el especial de Eurovision de la NRK el espectador asiste al resultado de las votaciones y al mismo tiempo a la reacción del público y de los propios participantes del Festival a través de la pantalla del escenario.

En las elecciones de Canal 9 en 2003, la presentadora acompañada por el movimiento de la plataforma de rotación navega entre los paneles mostrando los datos de 
participación y los resultados de las votaciones en las elecciones autonómicas. El panel no tiene ninguna sujeción física $y$, por tanto, no hay ningún problema para ocultar la naturaleza virtual de la escenografía.

TVE en 2004 con motivo del enlace real de los Príncipes de Asturias realiza un gran esfuerzo, reconstruyendo en 3D la Catedral de la Almudena de Madrid. De esta forma los espectadores conocen las novedades del enlace desde el lugar en el que se va a celebrar el acontecimiento. El paso del plató de televisión a la Catedral se produce en tiempo real con un resultado visual más que notable.

El trabajo que realiza la BBC con motivo de las elecciones de 2005 ejemplifica la capacidad de la escenografía virtual para determinar el relato de un programa de televisión. El entorno virtual permite al presentador estar de forma casi simultánea en la Cámara de los Comunes, recorrer Downing Street o pasearse por encima del mapa de Gran Bretaña, mostrando en 3D el resultado de las votaciones.

BBC News, recrea una escenografía hiperrealista en la que el presentador interactúa con los gráficos en 3D apuntando, dirigiendo y mostrando en definitiva, la información en tiempo real.

Por último, el especial electoral de la BBC de 2009, supone un ejercicio de contención y sobriedad en el uso del aparato audiovisual. El escenario apenas esboza algunos iconos representativos de los países miembros de la Unión Europea. El protagonismo absoluto es de los gráficos con los que el presentador interactúa para mostrar la información que va llegando de los distintos países. Series de animación 3D para televisión como Pocoyó, de la productora española Zinkia o largometrajes de gran éxito comercial como Up, de la factoría Disney ya están apostando por un uso del 3D basado en la simplicidad.

En sus comienzos en la década de los 90', los escenarios virtuales hacían un uso contenido del 3D obligados por la escasa capacidad de las tarjetas gráficas para reproducir todo el detalle. Hoy día las técnicas de representación 3D son capaces de reproducir hasta el más mínimo fragmento presente en la realidad. Sin embargo, algunos creadores audiovisuales de vanguardia como Disney, Zinkia o la BBC empiezan a darse cuenta de que no es necesario construir sus historias basándose siempre en el hiperrealismo como técnica de representación. Las herramientas infográficas y el 3D son algo más que un vehículo para reproducir la realidad, tienen la capacidad de acercarse a la esencia de lo representado. Simplificar la representación de un rostro, un paisaje o un objeto, permite quedarse con lo fundamental, extraer su esencia. En esta nueva concepción, el objetivo ya no es el realismo. Lo sustancial es que la composición final sea verosímil, represente una realidad tangible, en definitiva, que tenga vida.

\section{Bibliografía}

Brinkmann, R. (1999) The art and science of digital compositing. Morgan Kaufmann Publishers.

Cruz Neira, C.; Sandin, D. J.; Defanti, T. A. (1993), "Surround-Screen Projection-Based Virtual Reality: The Design and Implementation of the CAVE". En: Siggraph. Los Ángeles. 
Fernández, C.. (2009) "Estratificaciones significantes de la imagen en la realización de programas informativos de televisión: potencialidades de la tecnología más allá de la espectacularización". Castellón, UJI.

Fujui, K; Hayashi, M; Yamamouchi, Y. (1996), "Virtual studio system for tv program production" En: IEEE Multimedia.

Galán, E. (2008): "Escenografía virtual en TV. Análisis del uso de escenografía virtual en la realización de un programa de televisión", en Revista Latina de Comunicación Social, 63, páginas 31 a 42. La Laguna (Tenerife): Universidad de La Laguna.

Recuperado el 15 de diciembre de 2008 de:

http://www.ull.es/publicaciones/latina/_2008/04/Galan_Cubillo.html

DOI: 10.4185/RLCS-63-2008-752-031-042 / CrossRef link

----- (2009): "El trabajo del presentador de televisión en un escenario virtual". Revista Latina de Comunicación Social, 64, páginas 143 a 150. La Laguna (Tenerife):

Universidad de La Laguna, recuperado el 6 -4-09

http://www.revistalatinacs.org/09/art/13_812_07_escenario/Esteban_Galan_Cubillo.htm $\underline{1}$

DOI: $10.4185 /$ RLCS-64-2009-812-143-150 / CrossRed link

García, A. (2007) "Principios de interactividad: televisión interactiva y realidad virtual" en Enlaces: revista del CES Felipe II, $n^{\circ} 7$.

Edsall, S. (2008) "The future of television graphics" en ACMSIGGRAPH

Gibbs , S. (et al.) (1998), "Virtual Studios: An Overview” En: IEEE Multimedia.

Grau, O.; Pullen, T.; Tomas, G. A.; (2004) "A combined studio production system for 3 -D capturingt of live action and inmersive actor feedback". En: IEEE Multimedia.

Gubern, R. (2000), El eros electrónico. Madrid: Taurus.

Hughes, D. (1996) "Virtual studio technology. The 1996 Eurovision Song Contest". En EBU Technical Review. Summer 1996.

López Silvestre, F. (2004), El paisaje virtual. El cine de Hollywood y el neobarroco digital. Madrid: Biblioteca Nueva.

Moshkovitz, M. (2000), The Virtual Studio. Boston: Focal Press.

Pareja E. (1998), Escenografía virtual. UD. 157. Madrid: IORTV.

----- (2005), Tecnología actual de televisión. Madrid: IORTV

Pérez Martínez, V. (2009): "Multimedialidad e interactividad en la cobertura informativa de las elecciones presidenciales de los Estados Unidos de 2008 en los cibermedios españoles. Revista Latina de Comunicación Social, 64, páginas 161 a 175. La Laguna (Tenerife): Universidad de La Laguna, recuperado el 10 de enero de 2010, en 
http://www.revistalatinacs.org/09/art/15_814_09_Obama/Victor_Perez_Martinez.html DOI: 10.4185/RLCS-64-2009-814-161-175 / CrossRed link

Popkin, D. (1997), "Virtual studios - the BBC's experience”. En: EBU Technical Review: Summer 1997.

Spengas, X. (2005), "Los contenidos informativos en las televisiones generalistas" en Ámbitos (nº 13-14) págs 59 a 77.

Vázquez, T. (2009): "Evaluación de la calidad de la programación infantil de las televisiones generalistas españolas", en Revista Latina de Comunicación Social, 64, páginas 844 a 861. La Laguna (Tenerife): Universidad de La Laguna, recuperado el 12 de enero de 2_20010 de http://www.revistalatinacs.org/09/art/866_CEU/67_83_Tamara_Vazquez.html DOI: 10.4185/RLCS-64-2009-866-844-861 / CrossRef link

Valero, J. L. (2008): "La infografía digital en el ciberperiodismo", en Revista Latina de Comunicación Social, 63, página 492 a 504. La Laguna (Tenerife): Universidad de La Laguna, consultado el 12 de enero de 2010, en:

http://www.ull.es/publicaciones/latina/08/42_799_65_Bellaterra/Jose_Luis_Valero.html DOI: 10.4185/RLCS-63-2008-799-492-504 / CrossRef link

Vidal Zanón, E. (2001), Visiocascos y tarjetas estereoscópicas. Valencia: UPV.

Wojdala, A.; Gruszewski, M.; Rysard, C.; (2000). "Real-time shadow casting in virtual studio", MGV (Machine Graphics and Vision) 9 (2000), n. 1/2 p. 315-329.

\section{Notas}

[1] Existen intentos de objetivar los análisis de productos audiovisuales como el ICT (Índice de Calidad Televisiva) que elabora el Observatorio de la Televisión de la Universidad Austral y que Vázquez (2009) emplea para analizar la programación infantil de las televisiones generalistas españolas. Según esta clasificación, la calidad técnica del programa supone el 30\% de la valoración final del programa. Dentro de este apartado se incluye la escenografía, la iluminación y la puesta en escena. Sin embargo, el análisis que ocupa este artículo tiene una pretensión fundamentalmente descriptiva y por tanto, no va a utilizar ningún baremo objetivable.

[2] Valero Sancho (2008) aborda el valor informativo que proporciona la infografía digital en todos los géneros periodísticos.

[3] Aunque el programa electoral tiene un carácter fundamentalmente informativo, la cadena se juega gran parte de su prestigio y por ello es habitual que se realicen grandes despliegues de medios humanos y técnicos de forma que la cobertura que se realice de los comicios sea lo más solvente posible (Galán, 2008). En España, por ejemplo, todas las cadenas ya están conectadas a la base de datos del Ministerio del Interior, y disponen por tanto de la información al mismo tiempo. Por tanto, el valor añadido que puede ofrecer la cadena es el modo de presentar esos datos y aquí es donde entra en juego la EV. 
[4] Pérez Martínez (2009) analiza la repercusión mediática sin precedentes que tuvo la elección de Barack Obama.

[5] La interacción en tiempo real con objetos 3D, supone una apuesta extraordinariamente ambiciosa dentro de la dinámica de trabajo habitual en televisión. Soengas (2005), al analizar el contenido informativo de las televisiones generalistas en España, constata una infrautilización de los recursos tecnológicos y una ausencia de propuestas innovadoras en la narrativa audiovisual. Los recursos tecnológicos son aprovechados para optimizar las rutinas operativas de trabajo, pero sus ventajas, difícilmente son trasladables al producto final.

* investigación financiada

El presente estudio ha sido realizado con la ayuda del Proyecto de Investigación "Nuevas Tendencias e hibridaciones de los discursos audiovisuales contemporáneos", financiado por la convocatoria del Plan Nacional de I+D+i del Ministerio de Ciencia e Innovación, para el periodo 2008-2011, con código CSO2008-00606/SOCI, y del Proyecto de Investigación "Tendencias actuales en la producción y realización de informativos para televisión: entre el espectáculo, el entretenimiento y la información”, financiado por la convocatoria de la Universitat Jaume I y Bancaja, para el periodo 2007-2010, con código 07I430-P1 1B2007-26, ambos bajo la dirección del Dr. Javier Marzal Felici.

\section{FORMA DE CITAR ESTE TRABAJO EN BIBLIOGRAFÍAS - HOW TO CITE THIS} ARTICLE IN BIBLIOGRAPHIES / REFERENCES:

Galán Cubillo, E. y Fernández Fernández, C. (2011): "La escenografía virtual en la retransmisión de grandes eventos", en Revista Latina de Comunicación Social, 66. La Laguna (Tenerife): Universidad de La Laguna, páginas 063 a 078 recuperado el de de 2 , de

http://www.revistalatinacs.org/11/art/924_Castellon/03_Esteban.html

DOI: $10.4185 /$ RLCS-66-2011-924-063-078 / CrossRef link

Artículo recibido el 12 de diciembre de 2010; aceptado el 16 de enero de 2011; publicado el 21 de enero.

Nota: el DOI es parte de la referencia bibliográfica y ha de ir cuando se cite este artículo. 